Biochem. Lett, Vol. 5, PP. 1 -17 (2010)

\title{
IMMUNOCHEMICAL IDENTIFICATION OF AN EPITHELIAL MEMBRANE ANTIGEN IN PATIENTS WITH BLADDER CANCER
}

\author{
A.M. El-Waseef ${ }^{1(*)}$, I.M. El-Dosoky ${ }^{2}$, M . $\operatorname{Radwan}^{3}$, \\ A.M. Zakaria ${ }^{4}$, N . El-Kholy ${ }^{5}$ and A.M. Attallah ${ }^{3}$ \\ ${ }^{1}$ Chemistry Dept., Faculty of Science, Mansoura University, Egypt \\ ${ }^{2}$ Pathology Dept., Faculty of Medicine, Mansoura University, \\ Egypt \\ ${ }^{3} R$ \& D Dept., Biotech. Research Center, New Damietta City, Egypt \\ ${ }^{4}$ Urology \& Nephrology Center, Faculty of Medicine, Mansoura \\ University, Egypt \\ ${ }^{5}$ Clinical Oncology and Nuclear Medicine Dept., Mansoura \\ University Hospitals, Mansoura, Egypt
}

\begin{abstract}
An epithelial membrane antigen (EMA) has been analyzed with Western blot at 130-kDa. ELISA was used for screening and diagnosis of EMA in urine samples of bladder cancer patients. EMA was detected in 43 out of 51 bladder cancer patients with detection rate $84 \%$, while it was detected in 22 out of 28 suspicious patients with detection rate $78.5 \%$. In addition, EMA was detected in 21 out of 51 bladder cancer-free patients with detection rate $41 \%$. Moreover EMA was detected in 1 out of 32 urine samples from healthy individuals with detection rate $3.1 \%$. The performance characteristics of ELISA as a rapid diagnostic assay of bladder carcinoma based on EMA detection in urine samples revealed that the sensitivity was $84 \%$, while the specificity was $96.9 \%$ among normal individuals. There was an extremely significant $(P<0.0001)$ evaluation of urinary EMA level in patients with bladder cancer compared to the level of healthy subjects. Also the levels of urinary EMA of suspicious patients and bladder cancer-free patients were highly significantly elevated compared to its level in healthy subjects. Furthermore, urinary EMA level of bladder cancer was significantly
\end{abstract}


$(P<0.0001)$ higher than its level in bladder cancer-free patients. EMA levels were progressively increased with grades and stages of bladder cancer. It is concluded that, EMA detected at $130 \mathrm{kDa}$ using Western blot and assayed using ELISA for screening and diagnosis of bladder cancer can be used with high sensitivity compared to cystoscopy and high specificity among healthy individuals. Also quantitative estimation of EMA level in the urine of bladder cancer patients can differentiate them from other bladder affections. Therefore, it is concluded that urine EMA assay may serve as a marker for bladder cancer assessment.

\section{INTRODUCTION}

Bladder cancer is the second most common cancer of the urinary tract, the fourth most prevalent cancer in males and the seventh most prevalent cancer in females ${ }^{[1]}$. Cystoscopy is considered the gold standard for diagnosis of bladder cancer but has not been used for screening because of associated costs and patient discomfort. The bladder cancers are commonly investigated due to the presenting symptoms such as haematuria, urinary frequencies, etc. Approximately $80 \%$ of patients with primary bladder cancer are low grade, superficial to mucosa and respond well to local resection and adjuvant therapy ${ }^{[2]}$. Urine cytology requires an experienced cytopathologist and has an insufficient sensitivity for the detection of bladder cancer ${ }^{[3]}$. Up to $25 \%$ of bladder cancer cases will be detected after they become invasive or metastatic, resulting in significantly lower 5-year survival rates $^{[4]}$.

Biomarkers are substances that can be measured quantitively by immunochemical means in tissues or body fluids to identify the presence of a cancer and possibly the organ where it resides, to establish the extent of the tumor burden before treatments to predict prognosis, and to monitor the response to therapy ${ }^{[5]}$. Epithelial membrane antigen (EMA) is a type of mucins which are a group of high molecular weight glycoproteins found on epithelial surfaces. In the bladder, they have a protective role, inhibiting bacterial and stone adhesion $^{[6]}$. In addition, the loss of cell architecture and polarity 
associated with malignant disease means that EMA, normally confined to luminal surfaces, is shed into the bloodstream and thus has potential as a tumor marker. Therefore, the present work is concerned with the identification and quantitative determination of EMA in the urine of patients with bladder cancer.

(*) Corresponding author. Tel +2 0502242388 / 460, Fax: 050-2246781, E-mail: drahmedelwaseef@yahoo.com

\section{SUBJECTS AND METHODS}

\section{Subjects:}

A total of 162 urine samples from Egyptian individuals (130 patients and 32 healthy volunteers) were included in the present study. The subjects were classified into 3 groups: bladder cancer patients $(n=51)$, suspicious patients $(n=28)$, bladder cancer-free patients $(n=51)$ and healthy volunteers $(n=32)$. The patients were $104(80 \%)$ males and 26 $(20 \%)$ females (age range $24-85$ years, mean, $59.33 \pm 11.64$ years) and were all diagnosed by abdominal ultrasound, computed tomography, magnetic resonance imaging, and/or bone scans, in addition to the histopathology and cystoscopy. The group of healthy volunteers was $20(62.5 \%)$ males and $12(37.5 \%)$ females with age range 32 - 55 years (mean, $36.22 \pm 8.2$ years).

From the 51 bladder cancer patients 46 were diagnosed by histopathology as transitional cell carcinoma (TCC) and 5 as squamous cell carcinoma (SCC). Sixteen out of the 28 suspicious patients had hyperplastic smear and 12 were with severe degree dysplasia. Forty out of the 51 bladder cancer-free patients were having inflammatory smear and 11 were having haematuria. The patients were classified according to tumor stage into T3 and T4 and according to tumor grade into GI, GII and GIII. 


\section{Identification of EMA in urine samples from bladder cancer patients: \\ SDS-PAGE and Western blot technique:}

Urine samples were subjected to SDS-PAGE, at $25 \mu \mathrm{l} /$ lane, using vertical slabs of $12 \%$ polyacrylamide by the method described by Laemmli (1970) ${ }^{[7]}$. Samples separated on SDS-PAGE were electrotransferred onto nitrocellulose $(\mathrm{NC})$ membrane $(0.45-\mu \mathrm{m}$ pore size; Sigma) in a protein transfer unit (Towbin et al., 1979) ${ }^{[8]}$. The NC membrane was blocked, using 5\% (w/v) non-fat dry milk dissolved in $0.05 \mathrm{M}$ Tris-buffered saline (TBS) containing $200 \mathrm{mM} \mathrm{NaCl}$ (pH 7.4), rinsed in TBS, and incubated with epithelial membrane monoclonal antibody (1:50) diluted in the blocking buffer, with constant shaking overnight. The blots were washed three times (10 min each) in TBS, followed by incubation for $2 \mathrm{~h}$ with goat anti-mouse IgG-alkaline phosphatase conjugate (Sigma) diluted 1:250 in TBS. After washing for further three times with TBS (10 min each), the blots were soaked in the substrate [pre-mixed 5-bromo-4-chloro-3-indolyl phosphate (BCIP) and nitro blue tetrazolium (NBT), in 0.1 M Tris buffer, $\mathrm{pH}$ 9.6] (ABC Diagnostics, New Damietta, Egypt). The color of the reaction was observed within $10 \mathrm{~min}$ and the reaction was then stopped by dipping the blots in distilled water.

\section{Detection of the $130 \mathrm{kDa}$ EMA in urine samples using ELISA technique:}

After optimization of the reaction conditions, flat-bottomed, polystyrene, microtiter plates (Costar, USA), were coated with diluted urine samples in the coating buffer to bind overnight to wells of ELISA plates. After blocking, $50 \mu \mathrm{l} /$ well of diluted urine $(1: 100$, in PBS with $0.05 \%$ (v/v) Tween 20, (PBS-T20)) were added to each well. Urine samples from healthy persons were used as negative controls. The plates were incubated at $37{ }^{\circ} \mathrm{C}$ for $2 \mathrm{~h}$, washed, and then incubated, at $37{ }^{\circ} \mathrm{C}$ for $1 \mathrm{~h}$ with anti-mouse $\mathrm{IgG}$ alkaline phosphatase (Whole Molecule, Sigma). The conjugate developed in goat was diluted $(1: 500)$ in $0.2 \%(\mathrm{w} / \mathrm{v})$ bovine serum albumin (BSA) in PBST20. After washing, the substrate (p-nitro-phenyl phosphate in $0.1 \mathrm{M}$ glycine buffer; $\mathrm{pH}$ 10.4) was added and the plates were incubated for 
$30 \mathrm{~min}$ at $37^{\circ} \mathrm{C}$. The reaction was stopped by $\mathrm{NaOH}$ and the optical densities (OD) were read at $490 \mathrm{~nm}$ using $\sum 960$ microplate autoreader (Metertech Inc, USA). The cut-off OD for ELISA positivity was set as mean OD plus three SD for the urine from healthy individuals (cut-off $=0.25$ ).

\section{RESULTS}

\section{Identification of EMA in urine samples:}

Urine samples from bladder cancer patients and healthy individuals were undergone SDS- PAGE, then stained with coomassie blue. The gel was visualized and photographed. The coomassie blue stained separated polypeptides have a wide range of molecular weights ranging from $215 \mathrm{kDa}$ to $18.3 \mathrm{kDa}$. EMA was identified at $130 \mathrm{KDa}$ using Western blot technique (Fig. 1).

\section{Qualitative determination of EMA in urine samples using ELISA technique:}

ELISA technique was used to manifest the presence of EMA in the urine of bladder cancer patients (Fig. 2). EMA was detected in 43 out of total 51 bladder cancer patients with detection rate $84 \%$, while it was detected in 22 out of 28 suspicious patients with detection rate $78.5 \%$. In addition, EMA was detected in 21 out of 51 bladder cancerfree patients with detection rate $41 \%$. Moreover, EMA was detected in 1 out of 32 urine samples from healthy individuals with detection rate 3.1\% (Fig. 3). The performance characteristics of ELISA as a rapid diagnostic assay of bladder carcinoma based on $130 \mathrm{kDa}$ EMA detection in urine samples revealed that sensitivity in the cancer patients was $84 \%$, while specificity was $96.9 \%$ among normal individuals.

\section{Quantitative estimation of EMA level in the urine samples:}

The levels of EMA $(\mu \mathrm{g} / \mathrm{ml})$ in the urine samples of different patients and healthy subjects are shown in Table 1. The urine levels of EMA of 
all groups of patients are highly significantly $(\mathrm{P}<0.001)$ elevated than the level of control subjects. The difference between EMA level of bladder cancer patients and that of bladder cancer-free patients is also highly significant $(\mathrm{P}<0.0001)$. Also the difference between EMA level of the suspicious group and that of bladder cancer-free group is significant $(\mathrm{P}<0.05)$ (Table 1).

\section{Quantitative estimation of EMA in different grades and stages of bladder cancer:}

The levels of urinary EMA $(\mu \mathrm{g} / \mathrm{ml})$ were progressively increased with tumor grade. EMA level in GIII is higher than that of the level in GII, which in turn is higher than the level in GI. No statistically significant difference was found in the levels of EMA between GI\&GII, GI\&GIII and GII\&GIII, (Table 2). However, urine levels of EMA marker in T4 stage is higher than that in T3 stage, although the difference between the averages of both stages is not statistically significant (Table 2). 


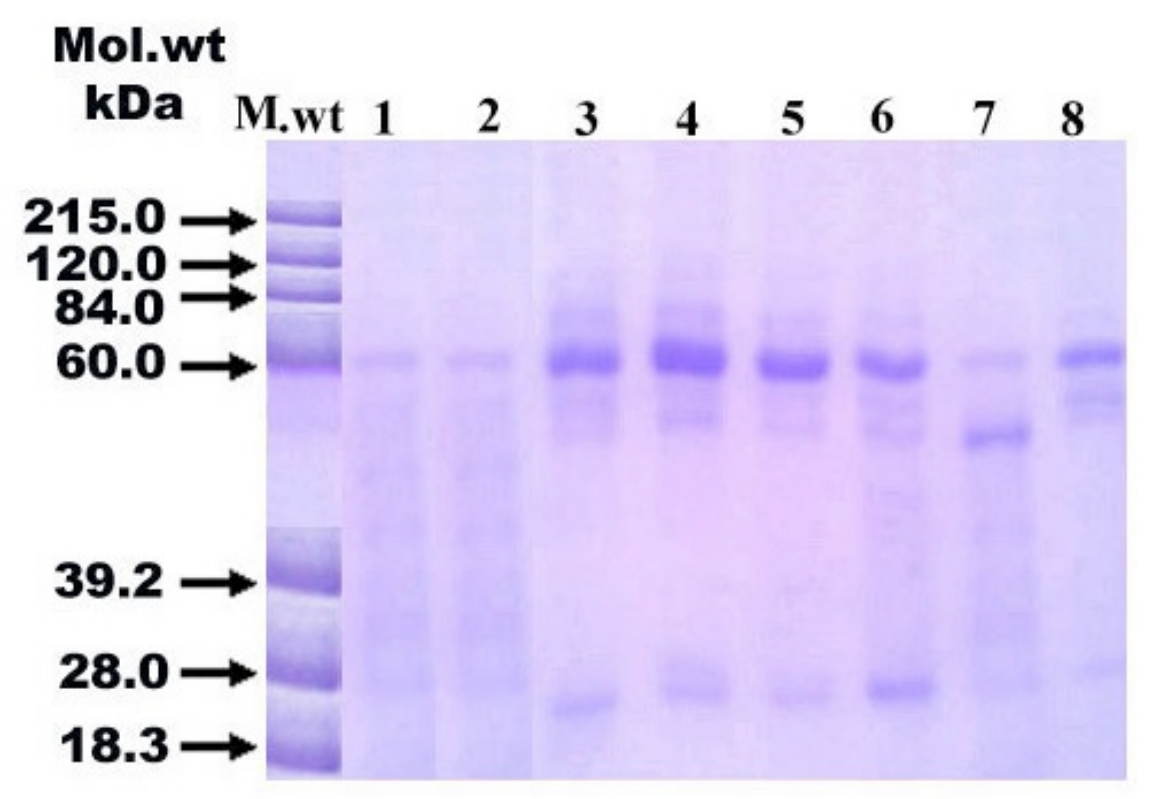

Figure 1: Shows that Coomassie blue stained SDS-PAGE of urine from bladder cancer patients and control individuals under reducing conditions. Lanes 1-2: urine samples of 2 healthy individuals, Lanes 3-4: urine samples from bladder cancer-free patients. Lanes 5-6: urine samples of suspicious patients. Lanes 7-8: urine samples from bladder cancer patients. Molecular weight markers $(\mathrm{Mr})$ includes: Myosin $(215.0 \mathrm{kDa})$, phosphorylase $\mathrm{B},(120.0$ $\mathrm{kDa})$, bovine serum albumin $(84.0 \mathrm{kDa})$, ovalbumin $(60.0 \mathrm{kDa})$, carbonic anhydrase $(39.2 \mathrm{kDa})$, trypsin inhibitor $(28.0 \mathrm{kDa})$, and lysozyme $(18.3 \mathrm{kDa})$. 




Figure 2. Illustrates the Detection of EMA in urine samples using ELISA. EMA levels are proportional to the developed color (grading from yellow in urine samples with undetected EMA levels to orange or red in urine samples with high EMA levels), with detection rate $66.15 \%$ of 130 patients.

Al- D1 wells: negative controls.

E1- H1 wells: positive controls.

A2 to H12 wells: urine samples of 88 patients with different pathologies of 130 patients included in the present study. 


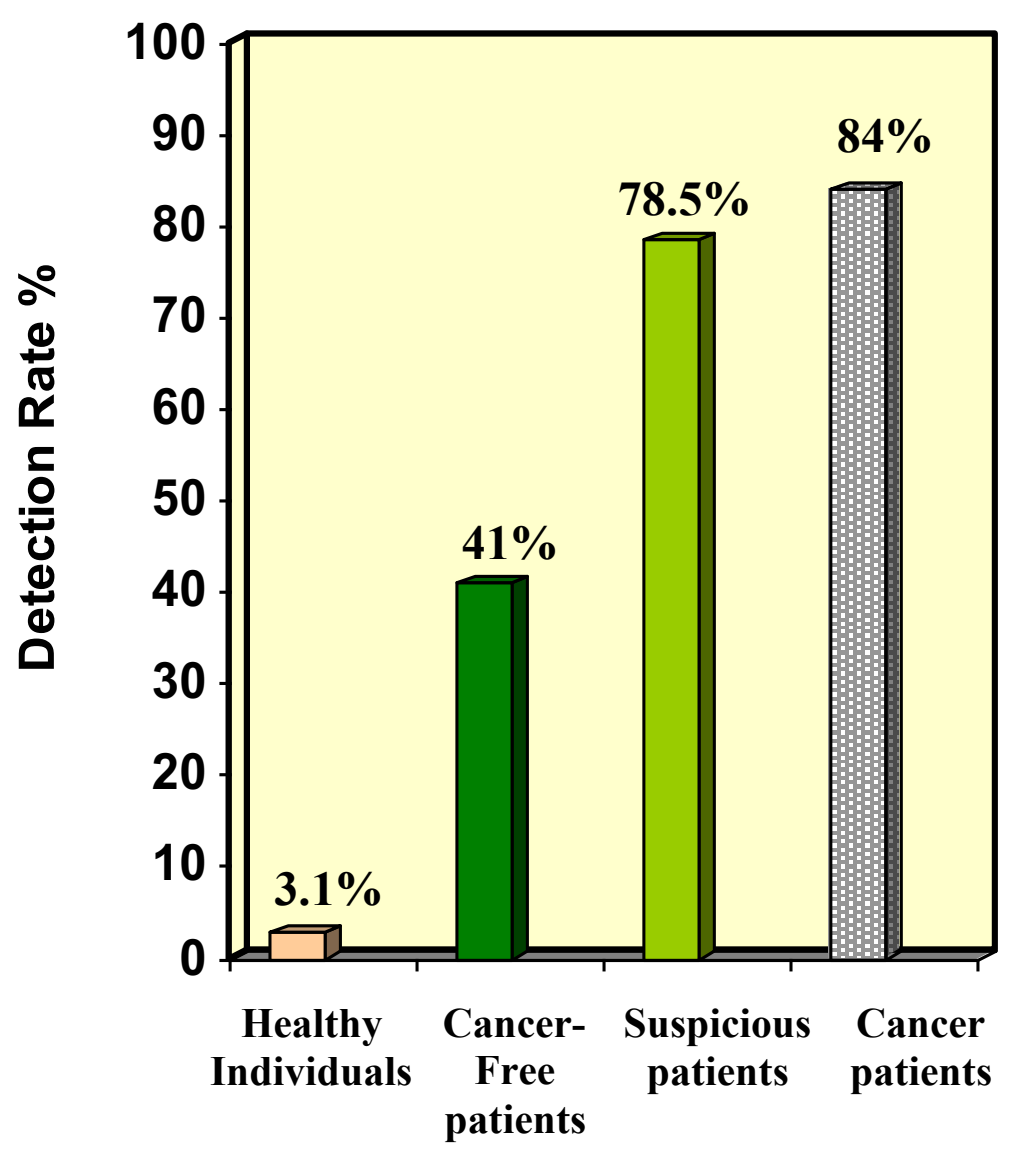

Figure 3: Illustrates the Detection rates of EMA in urine samples of bladder cancer patients compared with those suspicious patients, bladder cancer-free patients and healthy individuals. 
Table 1: Presents Quantitative estimation of EMA level in the urine samples of bladder cancer patients, suspicious patients and bladder cancer-free patients compared with its level in the urine samples of healthy subjects.

\begin{tabular}{||l|l|l||}
\hline \multirow{2}{*}{ Pathological status } & \multicolumn{2}{|c|}{ EMA $(\boldsymbol{\mu g} / \mathbf{m l})$} \\
\cline { 2 - 3 } & Range & $\mathbf{M} \pm \mathbf{S D}^{\infty}$ \\
\hline \hline $\begin{array}{l}\text { Bladder Cancer patients } \\
(\mathbf{n}=\mathbf{5 1})\end{array}$ & $0.6-5.1$ & $2.45 \pm 1.86^{*} \bullet$ \\
\hline \hline $\begin{array}{l}\text { Suspicious patients } \\
\text { (n=28) }\end{array}$ & $0.4-3.2$ & $1.87 \pm 0.86^{*} \bullet \bullet$ \\
\hline \hline $\begin{array}{l}\text { Bladder Cancer-Free patients } \\
(\mathbf{n}=\mathbf{5 1})\end{array}$ & $0.34-2.7$ & $1.38 \pm 0.95^{*}$ \\
\hline \hline $\begin{array}{l}\text { Healthy subjects } \\
(\mathbf{n}=\mathbf{3 2})\end{array}$ & $0.1-1.2$ & $0.53 \pm 0.18$ \\
\hline
\end{tabular}

${ }^{\infty} \mathrm{M} \pm \mathrm{SD}:$ Mean \pm standard deviation.

* highly significant $(\mathrm{P}<0.0001)$ elevation of the levels of EMA in groups of patients compared with the level of healthy subjects.

- highly significant $(\mathrm{P}<0.0001)$ elevation of the level of EMA in patients with bladder cancer compared with the level of bladder cancer-free patients.

- significant $(\mathrm{P}<0.05)$ elevation of the level of EMA in suspicious patients compared with its level in bladder cancer-free patients. 
Table 2: Presents Levels of urine EMA of bladder cancer patients according to grades and stages.

\begin{tabular}{|c|c|c|c|c|}
\hline Tumor & No. Of & FM 1 ( 1 & \multicolumn{2}{|c|}{ ANOVA } \\
\hline Grade I & 7 & $1.657 \pm .876$ & \multirow{3}{*}{$\begin{array}{l}\text { Between } \\
\text { groups }\end{array}$} & \multirow{3}{*}{$(P>0.05)$} \\
\hline Grade II & 9 & $2.350 \pm 1.758$ & & \\
\hline Grade III & 35 & $2.466 \pm 1.68$ & & \\
\hline $\begin{array}{l}\text { Tumor } \\
\text { Stage }\end{array}$ & $\begin{array}{l}\text { No. of } \\
\text { patients }\end{array}$ & EMA $(\mu \mathrm{g} / \mathrm{ml})$ & \multirow{3}{*}{$\begin{array}{l}\text { Between } \\
\text { groups }\end{array}$} & \multirow{3}{*}{$(P>0.05)$} \\
\hline $\mathbf{T 3}$ & 11 & $2.09 \pm 1.15$ & & \\
\hline $\mathbf{T 4}$ & 20 & $2.90 \pm 2.47$ & & \\
\hline
\end{tabular}

\section{DISCUSSION}

Egyptian bladder cancer has two major types, namely, schistosomal tumors that are associated with Schistosoma haematobium infestation and non-schistosomal tumors, which are similar to the western type of transitional cell carcinoma ${ }^{[9]}$. Bilharzial related bladder cancer constitutes $30.3 \%$ of all cancers in Egypt, ranking first among the reported malignancies in Egyptians ${ }^{[10]}$. Clinically and pathologically, bladder tumors can be categorized as superficial low-grade papillary lesions and high-grade in situ or invasive malignancies ${ }^{[11]}$. 
Early diagnosis is critical for maximizing the cure rate of bladdercancer patients ${ }^{[12]}$. Definitive diagnosis requires cystoscopy plus biopsy, which generally follows detection of tumor mass on preliminary imaging procedures like excretory urography and/or ultrasonography. In muscle invasive disease, further imaging studies like scintigraphy, computed tomography (CT) or magnetic resonance imaging (MRI) may be needed to detect pelvic organ extension and metastases ${ }^{[13]}$. Follow-up cystoscopy is recommended for all bladder cancer patients, even those with low-risk (stage a-grade 1, TaG1) tumours, because bladder cancer has the highest recurrence rate of all cancers ${ }^{[14]}$. The limitations of cytology and the invasiveness and the high cost of urethrocystoscopy for detecting bladder cancer have generated interest in other noninvasive diagnostic tools. In the last decade, the development of new biomarkers has given us new tests in the detection and follow-up of bladder cancer ${ }^{[15]}$.

Biomarkers are substances that can be measured quantitively by immunochemical means in tissue or body fluids to identify the presence of a cancer and possibly the organ where it resides, to establish the extent of the tumor burden before treatments to predict prognosis, and to monitor the response to therapy. The molecules that now are classified as tumor markers is considerable, including, tumorassociated antigens, nuclear and specific proteins, enzymes, isoenzymes, genes, oncogenes and their products ${ }^{[16]}$. Several urinary markers for cell carcinoma have been investigated, including, soluble and cell associated urine markers for bladder cancer. These markers have been described in detail in several recent reviews ${ }^{[17]}$.

In the present study urine EMA was evaluated as a tumor marker in patients with bladder cancer. It was detected using ELISA and estimated at $130 \mathrm{KDa}$. Several previous authors identified EMA in different body fluids as a high-molecular-weight glycoprotein (from 35 to $1500 \mathrm{kDa})^{[18,19,20]}$.

EMA was detected in cancer patients with a detection rate of $84 \%$, while the rate was $78.5 \%$ in suspicious patients. In addition, the detection rate was $41 \%$ in bladder cancer-free patients compared to a detection rate of $3.1 \%$ in healthy individuals. Urinary EMA was predicted in bladder cancer patients with high sensitivity $84 \%$, while 
specificity was $96.9 \%$ among normal individuals. Several authors used other bladder cancer tumor markers with different sensitivities and specificities. López et al. (2003) ${ }^{[21]}$ used tissue polypeptide antigen (TPA) for the detection of bladder cancer with sensitivity of $45 \%$ and specificity of $73 \%$. Myers-Irvin et al. (2005) ${ }^{[22]}$ used bladder cancer-1 (BLCA-1) as a bladder tumor marker with sensitivity of $80 \%$ and specificity of $87 \%$. Loeshwar et al. (2005) ${ }^{[23]}$ detected both primary and recurrent tumors using the combined hyaluronic acidhyaluronidase test with a sensitivity ranging from $83 \%$ to $94 \%$ and a specificity of approximately $80 \%$. Lokeshwar and Getzenberg (2006) ${ }^{[17]}$ used nuclear matrix proteins 22 (NMP22) to predict bladder cancer patients with a sensitivity ranging from $47 \%$ to $100 \%$ and a specificity ranging from $60 \%$ to $80 \%$.

The present results revealed that EMA levels in the urine of patients of the three groups were significantly elevated than its level in subjects of the control group. This means that EMA, as a tumor marker, can differentiate between the patients with manifested bladder cancer and suspected ones rather than the control subjects. Also EMA estimation can differentiate between bladder cancer patients and patients with other affections (Table 1). Xiang et al. (2005) ${ }^{[24]}$ had detected urine EMA in patients with bladder transitional cell carcinoma (BTCC) and found no significant differences between patients with BTCC, patients with cystitis glandularis and patients with benign urine disease, or between primary and recurrent cancer patients.

EMA in different grades of bladder cancer was quantified. The concentration of urinary EMA was increased with progression of the tumor grade. The concentration in GIII was higher than in GII which in turn was higher than in GI, although no statistically significant differences were found between these grades (Table 2). As early as 1994 Hruban et al. ${ }^{[25]}$ found that, P53 expression was rarely altered in grade 1 TCC. Tanaka et al. (1994) ${ }^{[26]}$ found that both EMA and carcenoembryonic antigen (CEA) were present more frequently in specimens from higher-grade and higher-stage tumors than lowergrade and lower-stage tumors. These authors concluded that immunocytochemistry for EMA assay is a more useful adjunctive 
method than CEA staining or conventional cytology for detection of tumor cells, especially in cases of low-grade bladder cancer.

Also EMA level was higher in T4 stage than that in T3 stage although no statistical significance was found. Schroeder et al. (2004) $^{[27]}$ found that the sensitivity of hyaluronic acid-hyaluronidase test to detect both low-grade/low stage and high-grade/high-stage tumors ranged from $75 \%$ to $100 \%$. López et al. (2003) ${ }^{[21]}$ found that TPA levels correlated with tumor stage, histologic grade, nodal stage, and metastatic stage and with urinary cytology in univariate analysis. Xiang et al. (2005) ${ }^{[24]}$ had detected urine MUC 1 in patients with BTCC and found no significant differences between patients with BTCC in all stages.

In conclusion EMA, detected at $130 \mathrm{kDa}$ using Western blot and assayed using ELISA for screening and diagnosis of bladder cancer, can be used with high sensitivity compared to cystoscopy and high specificity among healthy individuals. Also quantitative estimation of EMA level in the urine of bladder cancer patients can differentiate them from other bladder affections. Therefore, it is concluded that urine EMA assay may serve as a marker for bladder cancer assessment.

\section{ACKNOWLEDGMENT}

The authors would like to thank Drs. M.M. Omran, R. El-Sherbeny and M. Kadry at R \& D Dept., Biotechnology Research Center, New Damietta City, Egypt for their kind help.

\section{REFERENCES}

1-Pashos, C.L.; Botteman, M.F.; Laskin, B.L. and Redaelli, A. (2002): Bladder cancer: epidemiology, diagnosis, and management. Cancer Pract., 10: 311-322.

2- Stein, J. P. ; Grossfrld G.D.; Ginsberg, D.A.; Esrig, D.;

Freeman,J.A.; Figueroa, A.J.; Skinner, D.G. and Cote, R.J.

(1998). Prognostic markers in bladder cancer: a contemporary 
review of the literature. J. Urol., 160: 645-659.

3-Ponsky, L.E.; Sharma, S.; Pandrangi, L.; Kedia, S.; Nelson, D.; Agarwal, A. and Zippe, CD. (2001): Screening and monitoring for bladder cancer: refining the use of NMP22. J. Urol., 166: 7578.

4 - Grossman, H.B.; Messing, E.; Soloway, M.; Tomera, K.; Katz, G.; Berger, Y. and Shen, Y. (2005): Detection of bladder cancer using a point-of-care proteomic assay. JAMA., 293: 810-906.

5 - Schwartz, M.K. (1995): Currents status of tumor markers. Scand. J. Clin. Lab. Invest., 55: 5-14.

6 - Simms, M.S.; Hughes, O.D.; Limb, M.; Price, M.R. and Bishop, M.C. (1999): MUC1 mucin as a tumour marker in bladder cancer. BJU Int., 84: 350-352.

7 - Laemmli, U.K. (1970): Cleavage of structural proteins during the assembly of the head of bacteriophage T4. Nature, 227: 680-685.

8 - Towbin, H.; Staehlin, T. and Gordon, J. (1979): Electrophoretic transfer of proteins from polyacrylamide gels to nitrocellulose sheets: procedure and some applications. Proc. Natl. Acad. Sci., USA, 76: 4350-4354.

9 - Ghoneim, M.; El-Mekresh, M.; El-Baz, M.; El-Attar, I. and Ashmallah, A. (1997): Radical cystectomy for carcinoma of the bladder, critical evaluation of the results in 1026 cases. J. Urol., 158: 393-399.

10 - Khaled, H.M.; Aly, M.S. and Mokhtar, N. (2004): Chromosomal aberrations in Cis and Ta bilharzial bladder cancer: a theory of pathogenesis. Urologic Oncology: Seminars and Original Investigations, 22: 443-447.

11 - Haukaas, S.; Daehlin, L.; Maartmann-Moe, H. and Ulvik, N.M. (1999): The long-term outcome in patients with superficial transitional cell carcinoma of the bladder: a single-institutional experience. BJU. Int., 83: 957-963.

12 - Planz, B.; Jochims, E.; Deix, T.; Caspers, H.P.; Jakse, G. and Boecking, A. (2005): The role of urinary cytology for detection of bladder cancer. Eur. J. Surg. Oncol., 31: 304-308.

13 - Carmack, A.J. and Soloway, M.S. (2006): The diagnosis and staging of bladder cancer: from RBCs to TURs. Urol., 67: 3-8. 
14 - Irani, J.; Mottet, N.; Caparro's, J.R. and Teillac, P. (2007): New Trends in Bladder Cancer Management. European Association of Urology, 333-340.

15 - Vrooman, O.P. and Witjes, J.A. (2008): Urinary markers in bladder cancer. Europ. Urol. 53: 909-916.

16 - Vinata, B.; Lokeshwar, Ph.D. and Marie, G.S. (2006): Urinary bladder tumor markers. Urologic Oncology: Seminars and Original Investigations, 24: 528-537.

17 - Lokeshwar, V.B. and Getzenberg, R.H. (2006): Voided urine markers. In: Textbook of Bladder Cancer. Lerner, S.P.; Schoenberg, M. and Sternberg, C. (Eds.), London, T\&F-Informa, pp 65-137.

18 - Hendrick, J.C.; Collette, J.; Claes, S. and Franchimont, P. (1988): Epithelial membrane antigen (EMA) distribution in various biological fluids. Eur J Cancer Clin Oncol., 24(10): 1589-1594.

19 - Tang, C.K.; Katsara, M. and Apostolopoulos, V. (2008): Strategies used for MUC1 immunotherapy: human clinical studies. Expert Rev. Vaccines, 7(7): 963-975.

20 - Lacunza, E.; Bara, J.; Segal-Eiras, A. and Croce, M.V. (2009): Expression of conserved mucin domains by epithelial tissues in various mammalian species. Res Vet Sci., 86(1): 68-77.

21 - López, V.M.; Galán, J.A.; Fernández-Suárez, A.; LópezCelada, S.; Alcover, J. and Filella, X. (2003): Usefulness of tissue polypeptide antigen in the follow-up of bladder cancer. Urol., 62(2): 243-248.

22 - Myers-Irvin, J.M.; Landsittel, D. and Getzenberg, R.H. (2005): Use of the novel marker BLCA-1 for the detection of bladder cancer. J Urol., 174: 64-68.

23 - Loeshwar, V.B.; Habuchi, T. and Grossman, B. (2005): Bladder tumor markers beyond cytology: International Consensus on bladder tumor markers. Urology, 66(1): 35- 63.

24 - Xiang, S.T.; Zhou, S.W.; Guan, W.; Hu, Z.Q.; Zhuang, Q.Y. and Ye, Z.Q. (2005): Value of quantitative examination of urine MUC1 in bladder transitional cell carcinoma. Di Yi Jun Yi Da Xue Xue Bao., 25( 8): 998-1000. 
25 - Hruban, R. H.; Van Der Riet, P. and Yener, S. E. (1994):

Brief report Molecular biology and the early detection of carcinoma of the bladder. The case of Hubert. H. Humphrey. $\mathbf{N}$. Eng. J. Med. 330, pp $1276-1278$.

26 - Tanaka, K.; Takashi, M.; Miyake, K. and Koshikawa, T. (1994): Immunocytochemically demonstrated expression of epithelial membrane antigen and carcinoembryonic antigen by exfoliated urinary cells in patients with bladder cancer. Urol. Int., 52 (3): 140-144.

27 - Schroeder, G.L.; Lorenzo-Gomez, M.F.; Hautmann, S.H.; Friedrich, M.G.; Ekici, S.; Huland, H. and Lokeshwar, V.(2004): A side-byside comparison of cytology and biomarkers, HA-HAase, hematuria detection, BTA-Stat, UBC-Rapid for bladder cancer detection. J Urol., 172, pp 1123-1126. 